SFB

Equity and the willingness to pay for green electricity:

823

Evidence from Germany

Mark Andor, Manuel Frondel, Stephan Sommer

Nr. 6/2018

$\mathcal{C}$

$\mathcal{C}$

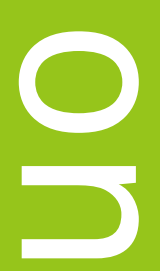

0

(1)

(D)

SFB
823
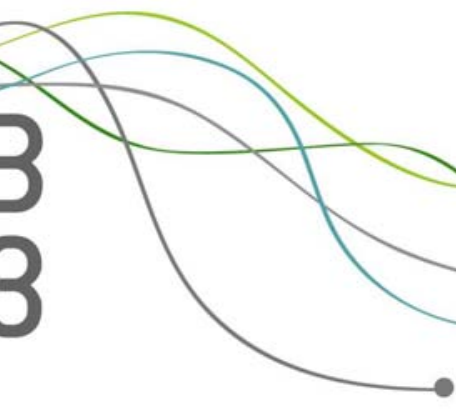



\title{
Equity and the Willingness to Pay for Green Electricity: Evidence from Germany
}

\author{
Mark Andor*, Manuel Frondel', Stephan Sommer*
}

March 8, 2018

\begin{abstract}
The production of electricity on the basis of renewable energy technologies is a classic example of an impure public good. It is often discriminatively financed by industrial and household consumers, such as in Germany, where the energy-intensive sector benefits from far-reaching exemptions, while all other electricity consumers are forced to bear a higher burden. Based on randomized information treatments in a stated-choice experiment among about 11,000 German households, we explore whether this coercive payment rule affects households' willingness-to-pay (WTP) for green electricity. Our central result is that reducing inequity by abolishing the exemption for the energy-intensive industry raises households' WTP, a finding that may have high external validity.
\end{abstract}

Keywords: Stated-choice experiment, Behavioral economics, Fairness.

JEL codes: D03, D12, H41, Q20, Q50.

Acknowledgements: We are grateful for invaluable comments and suggestions by Lorenz Gtte, Andreas Lange, Colin Vance as well as for feedback from the audiences at the IAEE (International Association for Energy Economics) conference 2017 at Vienna and the EnInnov2018 symposium at Graz. We gratefully acknowledge financial support by the Collaborative Research Center "Statistical Modeling of Nonlinear Dynamic Processes" (SFB 823) of the German Research Foundation (DFG), within Project A3, "Dynamic Technology Modeling", and by the Federal Ministry of Education and Research (BMBF) under grant 03SFK4B0 (Kopernikus Project ENavi).

*RWI Leibniz Institute for Economic Research

${ }^{\dagger}$ RWI Leibniz Institute for Economic Research and Ruhr University Bochum 


\section{Introduction}

Ample empirical evidence suggests that equity motives play a key role in many areas, such as international climate negotiations (Lange and Vogt, 2003; Kesternich et al., 2014; Vogt, 2016), as well as taxation (Esarey et al., 2012; Höchtl et al., 2012; Kallbekken et al., 2010). Another important field is the price setting of private goods (Kahneman et al., 1986), for which there is evidence that people are more likely to be willing to pay for a good when its price is perceived as fair, which crucially depends on whether other customers pay the same price or whether there is price discrimination. In response to the bulk of empirical evidence, economists developed theoretical models to account for fairness motives (Bolton and Ockenfels, 2000; Fehr and Schmidt, 1999; Rabin, 1993).

Thus far, the only study that, based on a student population, has analyzed the effect of fairness on the willingness-to-pay (WTP) for a public good is Ajzen et al. (2000). Our paper contributes to this line of inquiry by empirically investigating the impact of fairness on the WTP for an impure public good. Based on randomized information treatments implemented in a stated-choice experiment among about 11,000 German households, we explore whether inequity, given by a coercive payment rule, affects households' WTP for green electricity. Participants were randomly split into three experimental groups and asked for their WTP for increasing the share of green electricity in Germany, using the single-binary-choice format.

One third of the sample households were explicitly informed about the existence of exemptions for the energy-intensive industry in bearing the burden of disseminating renewable energy technologies and are then asked about their WTP for green electricity. Another third of the sample households received the same information, but was requested to reveal their WTP if these exemptions were to be abolished. The remaining third of households did not receive any further information when they were asked about their WTP. Using this study design, we aim at testing two hypotheses. On the one hand, we hypothesize that abolishing the exemption rule for the energy-intensive indus- 
try increases households' WTP for green electricity (equity hypothesis). On the other hand, providing information on the industry exemption decreases households' WTP for green electricity (salience hypothesis).

To investigate the WTP for (impure) public goods, hypothetical choices are typically employed (e.g. Carson, 2012). A caveat of the stylized decision environment of hypothetical studies is that they likely suffer from hypothetical bias (Blumenschein et al., 2008): respondents may affirm a WTP question, although this decision does not necessarily reflect their true preferences. However, assuming that hypothetical bias affects all treatments of our experiment alike, we argue that differences across treatments, that is, treatment effects should be unbiased.

Our cental result is that abolishing the exemption for the energy-intensive industry raises households' WTP for green electricity. Most striking is the size of the effects: abolishing the exemption in contributing to this impure public good almost doubles the acceptance rate for a given burden, a larger effect than when quartering this burden. Our empirical finding that reducing inequity in the distribution of cost increases the acceptance

of bearing these costs may have high external validity, that is, it may have far-reaching implications for policy-making in other fields where exemptions exist as well, for instance in carbon tax schemes (Bjørner and Jensen, 2002; Martin et al., 2014; Rivers and Schaufele, 2015; Yamazaki, 2017).

In the following section, we explain Germany's promotion system, followed by a concise description of our experimental setting and the database in Section 3 and 4. Section 5 presents the empirical results. The last section summarizes and concludes.

\section{Renewable Promotion in Germany}

Producing green electricity on the basis of renewable energy technologies is a classic example of an impure public good, whose consumption simultaneously generates a pri- 
vate and a public utility (see e. g. Kotchen, 2006): While consumers pay a price premium for being provided with green electricity, thereby enjoying a warm glow, greenhouse gas emissions that otherwise originate from fossil-based generation will be reduced by increasing green electricity production.

Yet, these advantages come at substantial costs: In many countries, green electricity is highly subsidized, with electricity consumers bearing the costs (IEA and IRENA, 2018). Energy-intensive companies, however, are frequently eligible for rebates to not endanger their international competitiveness. This holds for instance in Denmark, France, and the UK (CEER, 2017), as well as in Germany, where the share of green electricity in total consumption has been quintupled since 2000, to around one third today (BMWi, 2017). Energy-intensive facilities are, by law, eligible for rebates if the following pre-conditions are fulfilled: (1) a facility's electricity consumption level exceeds 1 million $\mathrm{kWh},(2)$ its electricity cost intensity exceeds a sector-specific percentage, ranging between 14 and $20 \%$, and (3) the facility implemented an energy management system. In 2016, about 2,800 facilities of around 2,100 companies were exempted from paying the full levy. These comprise about $4 \%$ of all companies of the industrial sector and accounted for about $40 \%$ of the industrial electricity consumption in Germany (BDEW, 2016).

Germany promotes electricity generation based on renewable energy technologies via a feed-in-tariff (FIT) system whereby green electricity has preferential access to the grid and is remunerated at technology-specific, above-market rates that are commonly guaranteed over a 20-year time period. Such FIT systems have been adopted in more than 100 countries throughout the world (REN21, 2017). Germany's FIT system, introduced in 2000 on the legal basis of the Renewable Energy Act (EEG), undoubtedly caused the tremendous increase in the capacity of renewable energy technologies from 12 to $104 \mathrm{Gi}$ gawatt between 2000 and 2016 (BMWi, 2017). To reach Germany's ambitious renewable goals of a share of $35 \%$ of green electricity in consumption in $2020,50 \%$ in 2030 , and $80 \%$ in 2050, these capacities must be expanded much further, to a multiple of today's renew- 
able capacities.

The costs for the promotion of green electricity are borne by consumers via a fixed surcharge on the net price of electricity, the so-called EEG levy. Since its introduction in 2000, the EEG levy rose from zero to 6.79 cents per kilowatt-hour (kWh) in 2018 (Figure 1), today accounting for about a quarter of the end-use electricity price (BDEW, 2018). In 2017, annual promotion costs amounted to about 25 billion Euros, which equals almost $1 \%$ of Germany's GDP.

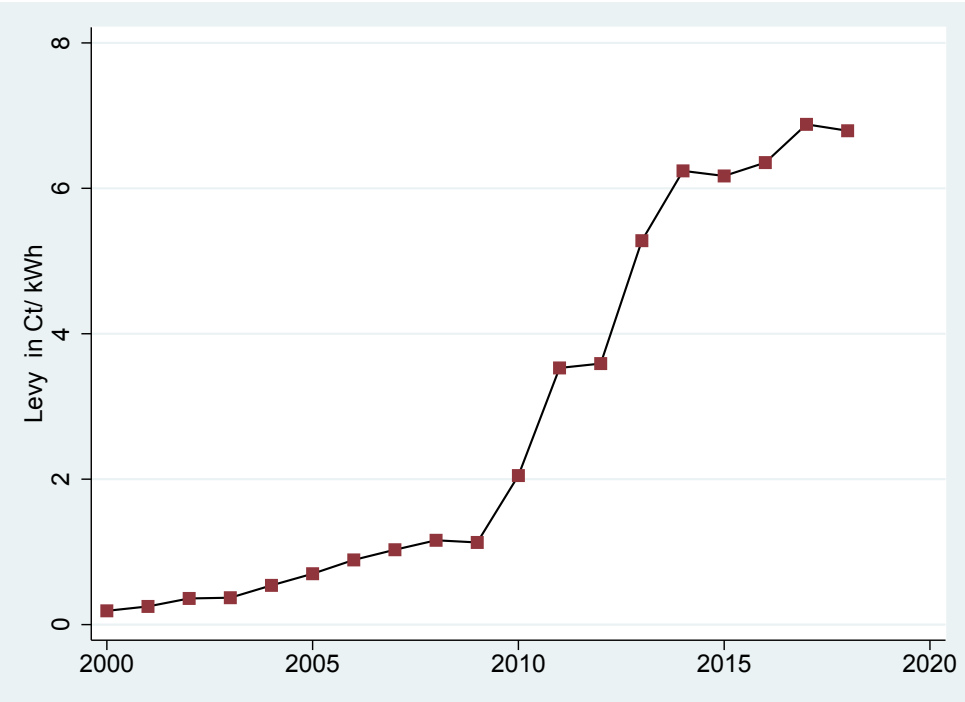

Figure 1: Levy for the Promotion of Renewable Energies in Germany. Source: BDEW (2018).

\section{Experimental Design}

We conducted a stated-choice experiment in which we inquired about participants' hypothetical willingness to pay for further increases in the costs of the promotion of renewable technologies. In detail, participants were asked whether they are willing to additionally pay $x \mathrm{ct} / \mathrm{kWh}$ for increasing the share of green electricity to $35 \%$ by 2020 (see Appendix A.1 for the exact questions). The amount $x \in\{1,2,4\}$ was randomly assigned and framed as a rise in the EEG levy. Given that this levy has increased by more than $4 \mathrm{ct} / \mathrm{kWh}$ since 2009 (see Figure 1) and a multiple of today's renewable capacity has to 
be deployed in oder to reach Germany's renewable goals, the amounts of 1 to $4 \mathrm{ct} / \mathrm{kWh}$ reflect a plausible range of future cost increases.

Participants were randomly split into three experimental groups: First, one third of the participants, belonging to what is called here the Retain Group, were informed about the exemption of the energy-intensive industry and were subsequently asked whether they would accept a further rise of $x \mathrm{ct} / \mathrm{kWh}$ in the EEG levy. Second, subjects who were randomly assigned to the group termed Abolish Group received the same information as those of the Retain Group, but were asked about their willingness to accept a given rise in the EEG levy if the exemptions for energy-intensive companies were to be abolished. Finally, subjects of the so-called Uninformed Group did not receive any further information before they were asked about whether they would accept a given levy increase.

Based on this study design, we aim at testing two hypotheses. First, we hypothesize that abolishing the exemption for energy-intensive firms increases households' WTP for green electricity (equity hypothesis). Second, providing information on the industry exemption decreases households' WTP for green electricity (salience hypothesis). The equity hypothesis is tested by comparing the share of households of the Abolish Group that are willing to pay the randomly given increase in the EEG levy with the respective share of the Retain Group. Similarly, the salience hypothesis is tested by contrasting the respective shares of the Retain and Uninformed Group.

While hypothetical choices are frequently employed to analyze the WTP for renewable energy technologies (e.g. Andor et al., 2017b), a potential shortcoming of this approach is that its stylized decision environment may induce participants to misreport their WTP, commonly referred to as hypothetical bias (e.g. Harrison, 2006; List and Gallet, 2001). To mitigate this bias, we opted for using a single-binary-choice format, as it is incentivecompatible for public goods with coercive payments (Carson and Groves, 2007, p. 192). Moreover, we argue that if hypothetical bias affects all treatments alike, differences across treatments, that is, treatment effects should be unbiased. This argument is supported by 
the empirical study of Ebeling and Lotz (2015): Investigating the impact of opt-in and opt-out tariffs, these authors find that while individuals choose "green" electricity tariffs more often in hypothetical than in market settings, treatment effects are indistinguishable for both settings.

\section{Data}

To elicit people's WTP for green electricity, we commissioned the survey institute forsa to carry out data collection. forsa maintains a panel of more than 10,000 households that is representative of the German-speaking population and collects the data using a state-ofthe-art tool that allows panelists to fill out the questionnaire using either a television or the internet. ${ }^{1}$ Respondents - here the household heads - retrieve and return questionnaires from home and can interrupt and continue the survey at any time. Household heads are defined as those individuals who are responsible for the financial decisions at the household level. While some socio-economic characteristics of our sample closely match the characteristics of the population of German household heads (see Table A1 in the appendix), sample household heads tend to be younger and better educated, suggesting that the empirical results are not representative for Germany. Notably, about one third of the respondents holds a college degree. Furthermore, with $38.2 \%$, the share of women in our sample is rather low, above all due to our decision to request household heads to participate in the survey.

The survey took place between December 23, 2015, and February 19, 2016, a period during which 11,375 individuals were recruited to fill out the questionnaire. 814 respondents abandoned the survey prior to the experiment, which corresponds to a dropout rate of $7.2 \%$. This rate is in line with other studies that are based on this household panel, see e. g. Andor et al. (2017a). As can be seen from Table 1, dropout rates do not vary across

\footnotetext{
${ }^{1}$ For more information on forsa's household panel, see http:/ / www.forsa.com.
} 
experimental groups, so that selection bias is not an issue.

Table 1: Descriptive Statistics for Select Variables

\begin{tabular}{|c|c|c|c|c|c|}
\hline Variable & Explanation & $\begin{array}{l}\text { Retain } \\
\text { Group }\end{array}$ & $\begin{array}{l}\text { Abolish } \\
\text { Group }\end{array}$ & $\begin{array}{l}\text { Uninformed } \\
\text { Group }\end{array}$ & $\begin{array}{l}\text { Whole } \\
\text { Sample }\end{array}$ \\
\hline Age & Age of respondent & 55.08 & $\begin{array}{c}54.80 \\
(-0.934)\end{array}$ & $\begin{array}{c}54.87 \\
(-0.689)\end{array}$ & 54.92 \\
\hline Female & Dummy: 1 if respondent is female & 0.382 & $\begin{array}{c}0.373 \\
(-0.790)\end{array}$ & $\begin{array}{c}0.382 \\
(0.024)\end{array}$ & 0.379 \\
\hline College degree & Dummy: 1 if respondent has a college degree & 0.338 & $\begin{array}{c}0.320 \\
(-1.522)\end{array}$ & $\begin{array}{c}0.332 \\
(-0.476)\end{array}$ & 0.330 \\
\hline Children & Dummy: 1 if respondent has children & 0.608 & $\begin{array}{c}0.617 \\
(0.786)\end{array}$ & $\begin{array}{c}0.612 \\
(0.338)\end{array}$ & 0.612 \\
\hline Income & Monthly household net income in $€$ & 2,881 & $\begin{array}{c}2,921 \\
(1.172)\end{array}$ & $\begin{array}{c}2,901 \\
(0.604)\end{array}$ & 2,901 \\
\hline \multirow[t]{2}{*}{ Green party } & Dummy: 1 if respondent is inclined to green party & 0.095 & $\begin{array}{c}0.096 \\
(0.091)\end{array}$ & $\begin{array}{c}0.113 \\
(2.327)^{*}\end{array}$ & 0.101 \\
\hline & Number of observations: & 3,739 & 3,774 & 3,862 & 11,375 \\
\hline
\end{tabular}

Note: t-test statistics for mean differences between the control group and the treatment groups are in parentheses. ${ }^{*}$ and ${ }^{* *}$ denote statistical significance at the $5 \%$ and the $1 \%$ level, respectively.

In fact, the descriptive statistics reported in Table 1 indicate that randomization was successful: with one exception, socio-economic characteristics are very similar across experimental groups, as is reflected by statistically insignificant t-test statistics for the mean differences in the covariates. The only exception is the indicator for pro-environmental attitudes, proxied here by the statement to be in favor of voting for Germany's green party. This is the case for about $10 \%$ of the respondents, which is in line with the results of the most recent federal election.

\section{Empirical Results}

The focus of our empirical analysis is a binary indicator that equals unity if a respondent is willing to accept a hypothetical rise of either 1,2, or $4 \mathrm{ct} / \mathrm{kWh}$ in the levy raised for the promotion of green electricity and zero otherwise. The descriptive results, presented in Table 2, show that the acceptance rates decrease substantially with the level of the levy increase, indicating internal validity of the responses. For example, across experimental groups, the share of respondents who accept an extra $4 \mathrm{ct} / \mathrm{kWh}$ is between about 13 and 
18 percentage points lower than for an increase of $1 \mathrm{ct} / \mathrm{kWh}$.

The experimental design of randomized treatments allows us to test our hypotheses on the basis of straightforward $t$ tests. As hypothesized, the acceptance rates differ substantially across experimental groups. For instance, the share of respondents of the Abolish Group who accept a randomly given increase in the EEG levy is about 35-40 percentage points higher than in the Retain Group, indicating that abolishing the exemption for energy-intensive firms raises the WTP for green electricity dramatically. This outcome supports the equity hypothesis, according to which fairness considerations play an important role with respect to the WTP for green electricity.

Table 2: Share of Respondents Who Accept an Increase of $x$ Cents/kWh in the EEG Levy to Reach Germany's Goal of a Share of Green Electricity of 35\% in 2020

\begin{tabular}{lcccccccc}
\hline & \multicolumn{2}{c}{ Retain Group } & & \multicolumn{2}{c}{ Abolish Group } & & \multicolumn{2}{c}{ Uninformed Group } \\
\cline { 2 - 5 } \cline { 7 - 8 } Levy Increase & \# Obs. & Share & & \# Obs. & Share & & \# Obs. & Share \\
\hline 1 Cent/kWh & 1,098 & $38.16 \%$ & & 1,121 & $73.60 \%$ & & 1,131 & $58.62 \%$ \\
& - & - & & - & $\left(18.00^{* *}\right)$ & - & $\left(9.87^{* *}\right)$ \\
2 Cents/kWh & 1,104 & $29.17 \%$ & & 1,048 & $67.56 \%$ & & 1,090 & $49.36 \%$ \\
& - & - & & - & $(19.29 * *$ & & - & $\left(9.90^{* *}\right)$ \\
4 Cents/kWh & 1,061 & $22.53 \%$ & & 1,069 & $60.90 \%$ & & 1,186 & $40.81 \%$ \\
& - & - & & - & $\left(19.48^{* *}\right)$ & - & $\left(9.44^{* *}\right)$ \\
\hline
\end{tabular}

Note: t-test statistics for the equality in means with respect to the control group are in parentheses. ${ }^{* *}$ denotes statistical significance at the $1 \%$ level.

Furthermore, as the salience hypothesis suggests, when respondents are explicitly informed about the existence of the industry exemption, as is done for those of the Retain Group, the acceptance rates are some 20 percentage points lower compared to that of the Uninformed Group. Most striking is the size of the effects: abolishing the exemption in contributing to this impure public good almost doubles the acceptance rates of a given burden, a larger effect than when quartering this burden. 


\section{Summary and Conclusion}

The perceived fairness of a price is widely recognized to be a critical determinant for people's WTP for a good (Ajzen et al., 2000). In this paper, we have explored how equity motives, particularly the inequality in the coercive payments for green electricity, affect the willingness-to-pay (WTP) for this impure public good. Based on randomized information treatments implemented in a stated-choice experiment among nearly 11,000 German households, we find that, on the one hand, abolishing the exemption for the energyintensive industry raises households' WTP for green electricity. On the other hand, when households learn about the prevalence of unequal contributions, our results indicate that this knowledge substantially decreases their WTP.

The empirical outcome that the distribution of costs highly matters for the acceptance of bearing these costs may be a general principle of high external validity, that is, it may have strong implications for policy-making in other fields, such as carbon taxation. For instance, Rivers and Schaufele (2015) suggest that the introduction of a carbon tax in British Columbia was only publicly accepted because the government reduced the tax rate for low-income households and companies. Apparently, as the acceptance of policies crucially hinges on the distribution of the associated costs, conceiving appropriate payment rules is key for the public acceptance of any policy instrument, not least greenhouse gas abatement measures. 


\section{A Appendix}

\section{A.1 Translation of the Description of the Experiment}

\section{Introduction to the Experiment}

"We will now ask about how much you are willing to pay for electricity that is generated with different energy sources and technologies. In what follows, we will call it your 'willingness-topay'."

\section{Information on the Promotion of Green Electricity}

"Germany's promotion of green electricity has contributed to the deployment of 93 Gigawatt (GW) of renewable energy technologies by 2014 and a share of $28 \%$ of green electricity in production. The German government aims at increasing the share of green electricity to $35 \%$ by 2020 . In Germany, the promotion of green electricity is financed via the so-called EEG levy. This levy has to be paid by every household for each unit of electricity consumed $(\mathrm{kWh})$ and amounts to $6.17 \mathrm{ct} / \mathrm{kWh}$ in 2015. Since the average electricity price in 2015 is $28.8 \mathrm{ct} / \mathrm{kWh}$, this corresponds to a share of some $21 \%$.

\section{Choice Situation}

Uninformed Group: "Are you willing to pay an increase in the EEG levy by $\mathrm{x}$ ct/kWh (to then $y$ ct/kWh) in order to achieve the goal of increasing the share of green electricity to 35\% by 2020?" Retain Group: "About 4\% of industrial companies, which cover about 40\% of the industrial electricity consumption, do not have to pay the full amount of the EEG levy. This exemption is intended to shield companies, so as not to undermine their international competitiveness. If the exemption for the energy-intensive is retained, are you willing to pay an increase in the EEG levy by $\mathrm{x} \mathrm{ct} / \mathrm{kWh}$ (to then $\mathrm{y} \mathrm{ct} / \mathrm{kWh}$ ) in order to achieve the goal of increasing the share of green electricity to $35 \%$ by 2020 ?"

Abolish Group: "About 4\% of industrial companies, which cover about $40 \%$ of the industrial electricity consumption, do not have to pay the full amount of the EEG levy. This exemption is 
intended to shield companies, so as not to undermine their international competitiveness. If the exemption were to be abolished, are you willing to pay an increase in the EEG levy by $\mathrm{xct} / \mathrm{kWh}$ (to then $\mathrm{y} \mathrm{ct} / \mathrm{kWh}$ ) in order to achieve the goal of increasing the share of green electricity to $35 \%$ by $2020 ? "$

\section{A.2 Table}

Table A1: Comparison of the Sample Household Heads with the Population of German Household Heads

\begin{tabular}{lcc}
\hline Variable & Sample & Germany (2016) \\
\hline 1 Person household & 0.245 & 0.411 \\
2 Person household & 0.483 & 0.340 \\
3 Person household & 0.139 & 0.123 \\
Household with 4 or more members & 0.133 & 0.127 \\
Household income $>€ 4,700$ & 0.119 & 0.128 \\
Age between 18 and 34 & 0.091 & 0.200 \\
Age between 35 and 64 & 0.640 & 0.524 \\
Age 65 and above & 0.269 & 0.276 \\
Female & 0.379 & 0.352 \\
College degree & 0.330 & 0.211 \\
\hline
\end{tabular}

Data for the population of German household heads is drawn from Destatis (2017). This data source asks the main earner to complete the questionnaire, whereas we ask the household member who usually makes financial decisions at the household level. Furthermore, the variable high income is top-coded at 4,500 EUR, while in our sample the upper threshold is at 4,700 EUR. 


\section{References}

Ajzen, I., Rosenthal, L. H., Brown, T. C., 2000. Effects of Perceived Fairness on Willingness To Pay. Journal of Applied Social Psychology 30 (12), 2439-2450.

Andor, M., Gerster, A., Sommer, S., 2017a. Consumer Inattention, Heuristic Thinking and the Role of Energy Labels. Ruhr Economic Papers \# 671.

Andor, M. A., Frondel, M., Vance, C., 2017b. Germany's Energiewende: A Tale of Increasing Costs and Decreasing Willingness-To-Pay. Energy Jornal 38 (SI 1), 211-228.

BDEW, 2016. Erneuerbare Energien und das EEG: Zahlen, Fakten, Grafiken (2016). Bundesverband der Energie- und Wasserwirtschaft.

BDEW, 2018. BDEW-Strompreisanalyse Januar 2018. Bundesverband der Energie- und Wasserwirtschaft, Berlin.

Bjørner, T. B., Jensen, H. H., 2002. Energy taxes, Voluntary Agreements and Investment SubsidiesA Micro-Panel Analysis of the Effect on Danish Industrial Companies' Energy Demand. Resource and Energy Economics 24 (3), 229-249.

Blumenschein, K., Blomquist, G. C., Johannesson, M., Horn, N., Freeman, P., 2008. Eliciting Willingness To Pay Without Bias: Evidence from a Field Experiment. Economic Journal 118 (525), $114-137$.

BMWi, 2017. Erneuerbare Energien in Zahlen. Bundesministerium für Wirtschaft und Energie, Berlin.

Bolton, G. E., Ockenfels, A., 2000. ERC: A Theory of Equity, Reciprocity, and Competition. American Economic Review, 166-193.

Carson, R. T., 2012. Contingent Valuation: A practical Alternative when Prices Aren't Available. Journal of Economic Perspectives 26 (4), 27-42.

Carson, R. T., Groves, T., 2007. Incentive and Informational Properties of Preference Questions. Environmental and Resource Economics 37 (1), 181-210. 
CEER, 2017. Status Review of Renewable Support Schemes in Europe. Council of European Regulators.

Destatis, 2017. Bevölkerung und Erwerbstätigkeit. Report ID: 2010300167004. Statistisches Bundesamt.

Ebeling, F., Lotz, S., 2015. Domestic Uptake of Green Energy Promoted By Opt-Out Tariffs. Nature Climate Change 5 (9), 868-871.

Esarey, J., Salmon, T. C., Barrilleaux, C., 2012. What Motivates Political Preferences? Self-Interest, Ideology, and Fairness in a Laboratory Democracy. Economic Inquiry 50 (3), 604-624.

Fehr, E., Schmidt, K. M., 1999. A Theory of Fairness, Competition, and Cooperation. Quarterly Journal of Economics 114 (3), 817-868.

Harrison, G. W., 2006. Experimental Evidence on Alternative Environmental Valuation Methods. Environmental and Resource Economics 34 (1), 125-162.

Höchtl, W., Sausgruber, R., Tyran, J.-R., 2012. Inequality Aversion and Voting on Redistribution. European Economic Review 56 (7), 1406-1421.

IEA, IRENA, 2018. IEA / IRENA joint policies and measures database. International Energy Agency and International Renewable Energy Agency, Paris and Masdar City.

URL http: / / www.iea.org/policiesandmeasures/renewableenergy /

Kahneman, D., Knetsch, J. L., Thaler, R. H., 1986. Fairness and the Assumptions of Economics. Journal of Business, S285-S300.

Kallbekken, S., Kroll, S., Cherry, T. L., et al., 2010. Pigouvian Tax Aversion and Inequity Aversion in the Lab. Economics Bulletin 30 (3), 1914-1921.

Kesternich, M., Lange, A., Sturm, B., 2014. The Impact of Burden Sharing Rules on the Voluntary Provision of Public Goods. Journal of Economic Behavior E Organization 105, 107-123.

Kotchen, M. J., 2006. Green Markets and Private Provision of Public Goods. Journal of Political Economy 114 (4), 816-834. 
Lange, A., Vogt, C., 2003. Cooperation in International Environmental Negotiations due to A Preference for Equity. Journal of Public Economics 87 (9), 2049-2067.

List, J. A., Gallet, C. A., 2001. What Experimental Protocol Influence Disparities Between Actual and Hypothetical Stated Values? Environmental and Resource Economics 20 (3), 241-254.

Martin, R., De Preux, L. B., Wagner, U. J., 2014. The Impact of a Carbon Tax on Manufacturing: Evidence from Microdata. Journal of Public Economics 117, 1-14.

Rabin, M., 1993. Incorporating Fairness into Game Theory and Economics. American Economic Review, 1281-1302.

REN21, 2017. Renewables 2017. Global Status Report. Renewable Energy Policy Network for the 21st Century.

Rivers, N., Schaufele, B., 2015. Salience of Carbon Taxes in the Gasoline market. Journal of Environmental Economics and Management 74, 23-36.

Vogt, C., 2016. Climate Coalition Formation when Players Are Heterogeneous and Inequality Averse. Environmental and Resource Economics 65 (1), 33-59.

Yamazaki, A., 2017. Jobs and Climate Policy: Evidence from British Columbia's Revenue-Neutral Carbon Tax. Journal of Environmental Economics and Management 83, 197-216. 


